\title{
Alcoholic Hypertriglyceridemia with Decreased Activity of Lipoprotein Lipase and Hepatic Triglyceride Lipase
}

\author{
Yoichi Hiasa, Kimio Nakanishi, Kouji Tada, Yuji Mizukami, Kouichi Akamatsu and Yasuyuki Ohta
}

\begin{abstract}
A 35-year-old male with alcoholic hypertriglyceridemia due to decreased lipoprotein lipase (LPL) and hepatic triglyceride lipase (HTGL) activities is reported. The patient had been drinking about $180 \mathrm{ml}$ of whiskey (equivalent to $80 \mathrm{~g}$ of $100 \%$ ethanol) every day for the last 17 years, and the highest levels of serum triglyceride (TG) and cholesterol were $5,120 \mathrm{mg} / \mathrm{dl}$ and $506 \mathrm{mg} / \mathrm{dl}$, respectively. Serum TG level returned to normal levels after complete alcohol abstinence. Further intake of ethanol resulted in an increase in serum TG to $326 \mathrm{mg} / \mathrm{dl}$ with a concomitant decrease in the serum levels of LPL and HTGL activities.
\end{abstract}

(Internal Medicine 32: 490-493, 1993)

Key words: hyperlipidemia, triglyceride, alcohol, high density lipoproteins (HDL)-cholesterol

\section{Introduction}

Alcohol drinkers frequently develop hyperlipidemia of type IV or $\mathrm{V}$, which mainly involves hypertriglyceridemia (1). The reduced activity of lipoprotein lipase (LPL) and hepatic triglyceride lipase (HTGL) as well as the enhanced secretion of very low density lipoprotein (VLDL) in the liver $(1,2)$ have been suggested to be associated with the development of type IV or V hyperlipidemia. However, previous studies have not dealt clearly with the direct effect of alcohol in this context. We experienced a case of type IV hyperlipidemia in a habitual drinker with marked hypertriglyceridemia $(5,120 \mathrm{mg} / \mathrm{dl})$, in which the reduced activity of LPL and HTGL was found to be partly responsible.

\section{Case Report}

A 35-year-old male who was a heavy drinker ( $80 \mathrm{~g}$ of $100 \%$ ethanol per day for 17 years), was found to have abnormal serum lipid levels at an annual check-up in July 1988, and he visited The third Department of Internal Medicine, Ehime University Hospital on October 24, 1988. High levels of triglycerides (TG) $(625 \mathrm{mg} / \mathrm{dl})$ and cholesterol $(280 \mathrm{mg} / \mathrm{dl})$ were found and the patient was observed on an out-patient basis. After frequent increases of the TG level, it rose to $5,120 \mathrm{mg} / \mathrm{dl}$ by April 11, 1990. He complained of fatigue, and was admitted for further investigation on June 25, 1990.

Figure 1 shows the changes in serum lipid levels before admission. Although the TG level was particularly high (up to $5,120 \mathrm{mg} / \mathrm{dl}$ ), both the TG and cholesterol levels returned to normal in May 1990, after abstinence from alcohol for 8 weeks.

On admission, his height was $163.3 \mathrm{~cm}$, weight $62.8 \mathrm{~kg}$, blood pressure $120 / 72 \mathrm{mmHg}$, and pulse rate $68 / \mathrm{min}$ (regular) No signs of anemia or jaundice were present, and the results of the chest examination was normal. The abdomen was flat, and the liver was palpable ( $1 / 2$ finger-breadth) in the midclavicular line. It was soft and the edge was dull. The spleen was not palpable, and no tenderness, ascites, or masses were detected in the abdomen. No edema was observed in the lower limbs and the neurological examination was normal.

Laboratory findings on admission are shown in Table 1. Urinalysis and hematological findings were normal. Biochemical tests revealed a slight elevation of gamma-glutamyl transpeptidase (GTP). As mentioned above, the high TG and cholesterol levels had resolved after the cessation of alcohol intake for 8 weeks. Although the lipoprotein components were present in normal proportions, the apoprotein A-I level was decreased.

An investigation to determine the etiology of the hypertriglyceridemia was performed after the ingestion of a low fat diet (Fig. 2). The patient was given a high carbohydrate diet [carbohydrate $(\mathrm{CH}) 340 \mathrm{~g}$, protein (Prot.) $90 \mathrm{~g}$, fat $5 \mathrm{~g}$, total, $1,800 \mathrm{kcal}$ ] from July 2 to July 8,1990 . After that he took a high fat diet (CH $180 \mathrm{~g}$, Prot. $90 \mathrm{~g}$, Fat $90 \mathrm{~g}$, total, 1,800 kcal) from July 9 to July 15 and a low fat diet (CH 300 g, Prot. 90 g, Fat 25 $\mathrm{g}$, total, $1,800 \mathrm{kcal}$ ) from July 16 to July 19 . Then he was given

From the third Department of Internal Medicine, Ehime University School of Medicine, Ehime

Received for publication July 6, 1992; Accepted for publication May 13, 1993

Reprint requests should be addressed to Dr. Yoichi Hiasa, Department of Internal Medicine, Ohzu Central Hospital, 5 Higashiohzu, Ohzu, Ehime 795, Japan 


\section{LPL and HTGL in Hypertriglyceridemia}

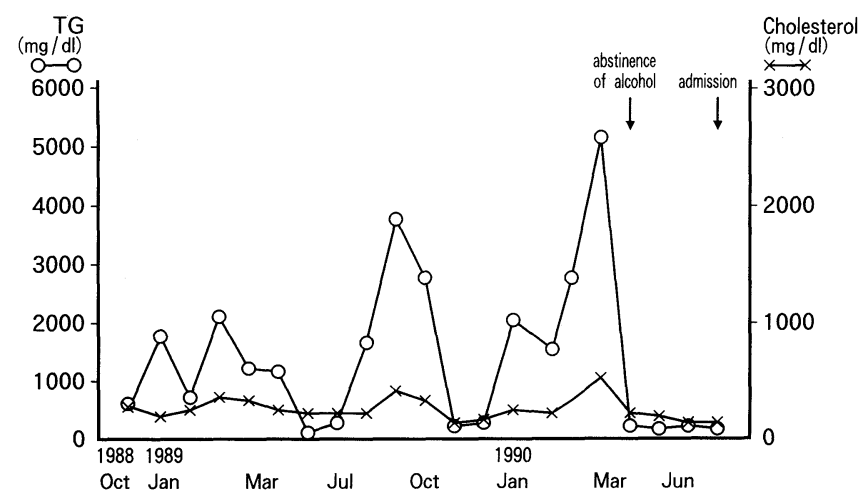

Fig. 1. The levels of serum triglyceride (TG) and cholesterol before hospitalization.

Table 1 Laboratory Findings on Admission

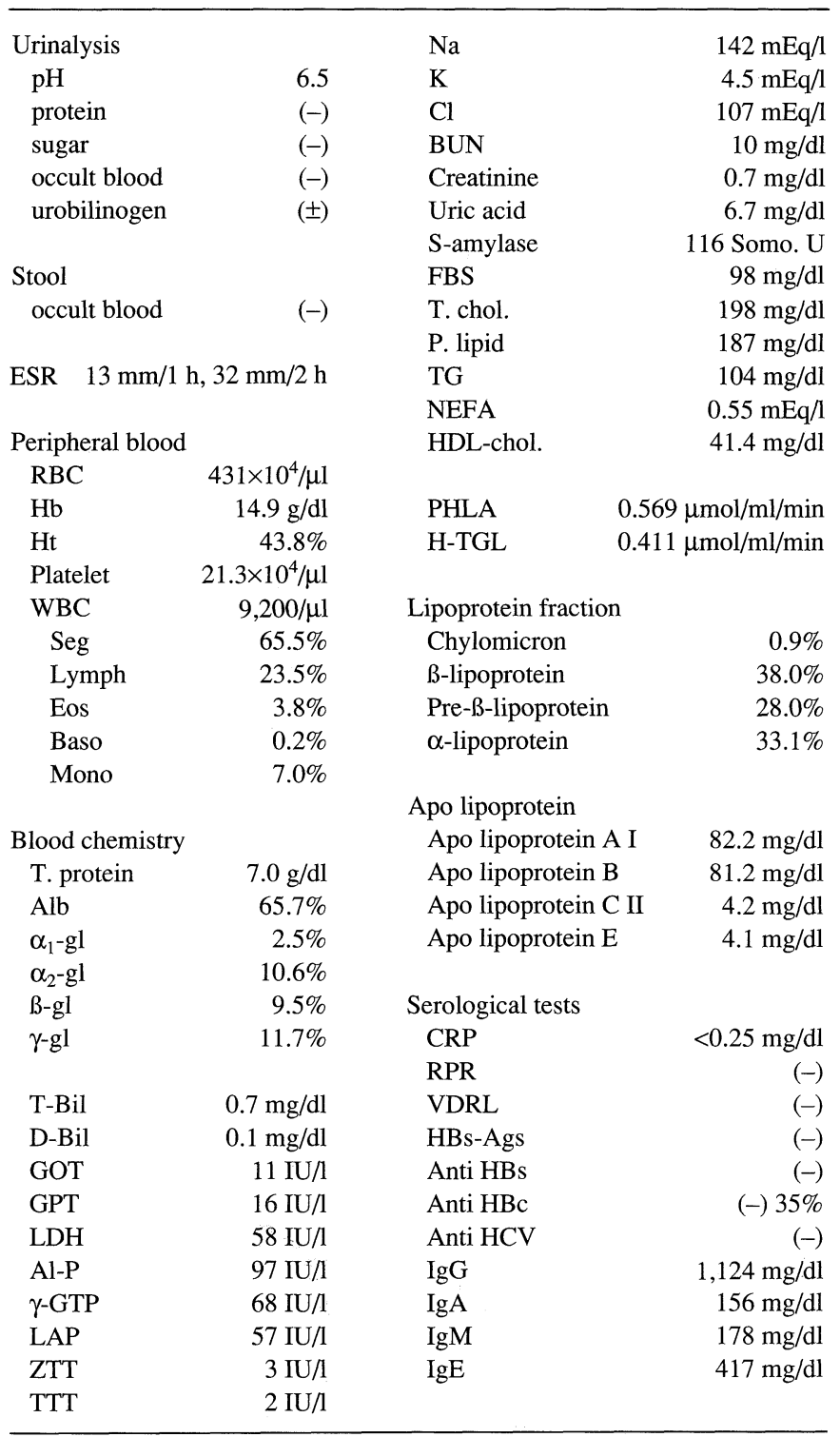

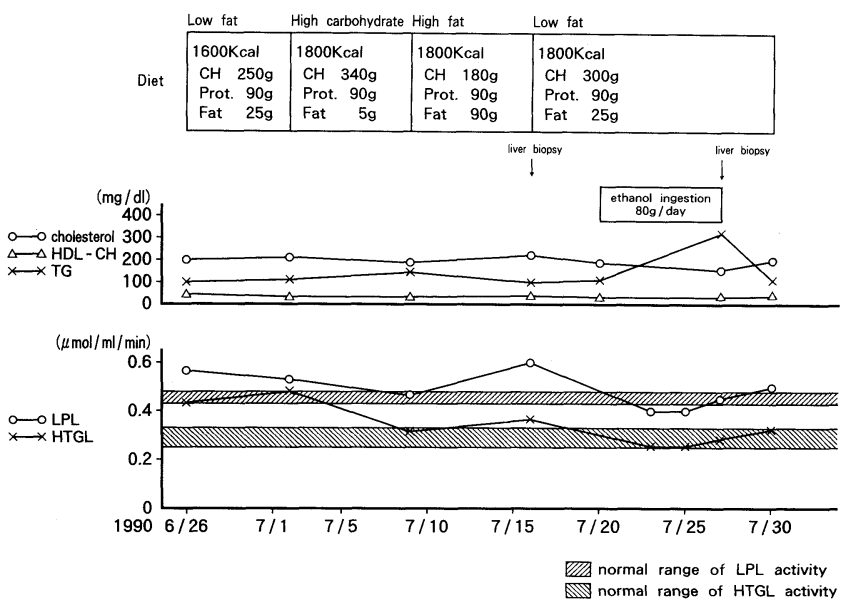

Fig. 2. Changes of serum lipid levels on each diet tolerance test. Serum triglyceride (TG) level was increased by taking ethanol. The levels of lipoprotein lipase (LPL) and hepatic triglyceride lipase (HTGL) activities were decreased during ethanol ingestion. $\mathrm{CH}$ : carbohydrate, Prot.: protein.
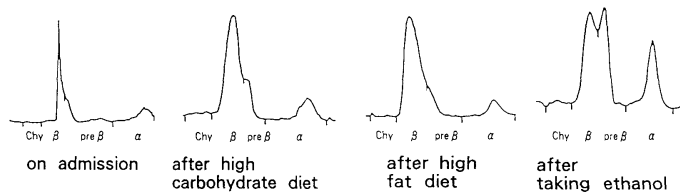
Lipoprotein fraction
Chylomicron (\%) 0.9
$\beta$-lipoprotein $\quad(\%) \quad 38.9$
Pre- $\beta$ - lipoprotein (\%) $\quad 28.0$
$\alpha$-lipoprotein (\%) 33.1
Apo lipoprotein
A I $(\mathrm{mg} / \mathrm{dl})$
B $(\mathrm{mg} / \mathrm{dl})$
C II $(\mathrm{mg} / \mathrm{dl})$
E $(\mathrm{mg} / \mathrm{dl})$

82.2
81.2
4.2
4.1

3.6
63.7
15.3
17.4

80.2
102.9
5.6
4.8

1.4
73.6
12.2
12.7

81.2
110.5
4.2
4.7

3.4
40.5
31.0
25.1

92.2
78.3
7.9
8.3

Fig. 3. Lipoprotein and apolipoprotein fraction patterns on each diet tolerance test. Chy: chylomicron.

a low fat diet with $80 \mathrm{~g}$ ethanol/day from July 20 to July 26 . The purpose of this study and procedures was explained and informed consent was obtained from the patient before entry into the study.

Although the serum cholesterol level was not affected by ethanol loading, the TG level increased from 119 to $326 \mathrm{mg} / \mathrm{dl}$ after 7 days. The high density lipoproteins (HDL)-cholesterol level remained low at all times.

Investigation of the lipoprotein fractions after ethanol loading revealed a high TG level and a relative increase in prebetalipoprotein (Fig. 3), while the cholesterol level was normal. This indicated a diagnosis of type IV hyperlipidemia. Assessment of the lipid composition in the lipoproteins after ethanol loading showed a decrease in HDL-cholesterol and an elevation of VLDL-TG (Fig. 4).

Measurement of the levels of LPL and HTGL at 10 minutes after the i.v. injection of $100 \mathrm{U} / \mathrm{kg}$ heparin during the loading tests showed that their levels fell after carbohydrate and ethanol 


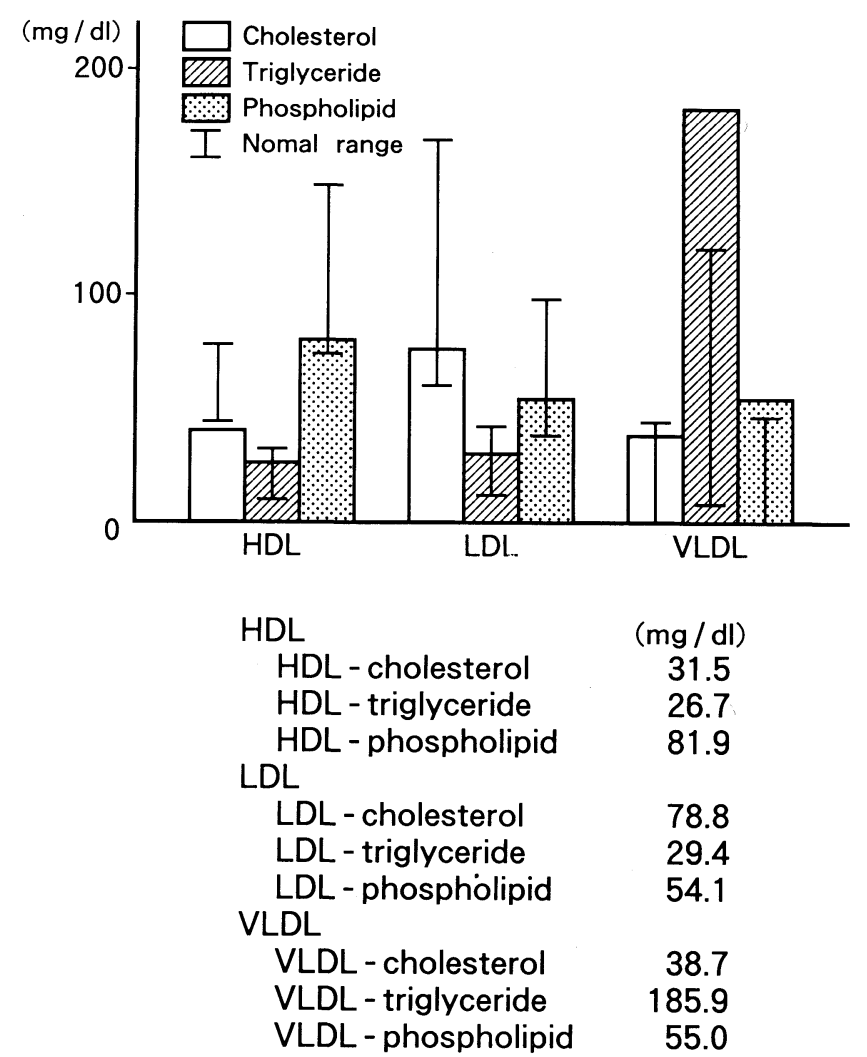

Fig. 4. Lipid composition in lipoproteins after ethanol loading. The value of HDL-cholesterol was low. VLDL-triglyceride was raised. loading (Fig. 2). No changes were detected in the liver function tests performed before and after ethanol loading or by abdominal ultrasonography. Liver biopsy specimen revealed no evidence of alcoholic liver fibrosis or any significant increase in fat droplets indicative of fatty liver (Fig. 5).

\section{Discussion}

LPL is an enzyme which breaks down TG within VLDL and chylomicrons, and HTGL metabolizes the TG in the intermediate density lipoproteins (IDL) formed by the action of LPL.

In the present patient, despite the absence of liver injury on liver biopsy both before and after ethanol loading, the levels of these enzymes were found to be reduced by ethanol loading compared with the baseline values.

According to Taskinen and associates (3), chronic alcohol intake increases the levels of LPL and HTGL. However, Crouse and Grundy (4) reported that alcohol intake did not affect these enzymes. Goldberg and associates (5) reported that the levels of LPL remained unchanged when a $40 \mathrm{~g}$ ethanol load was given to healthy volunteers, while that of HTGL fell transiently to reach the lowest value after 6 hours. Although the elevation of TG and VLDL levels by alcohol intake could be attributed to the reduced activity of HTGL, there have been no previous reports on the direct suppression of the activity of these enzymes by chronic alcohol intake, as seen in the present patient.

In addition, apoproteins $\mathrm{C}$-II and $\mathrm{E}$ were increased in this patient (Fig. 3). These apoproteins are the respective activating
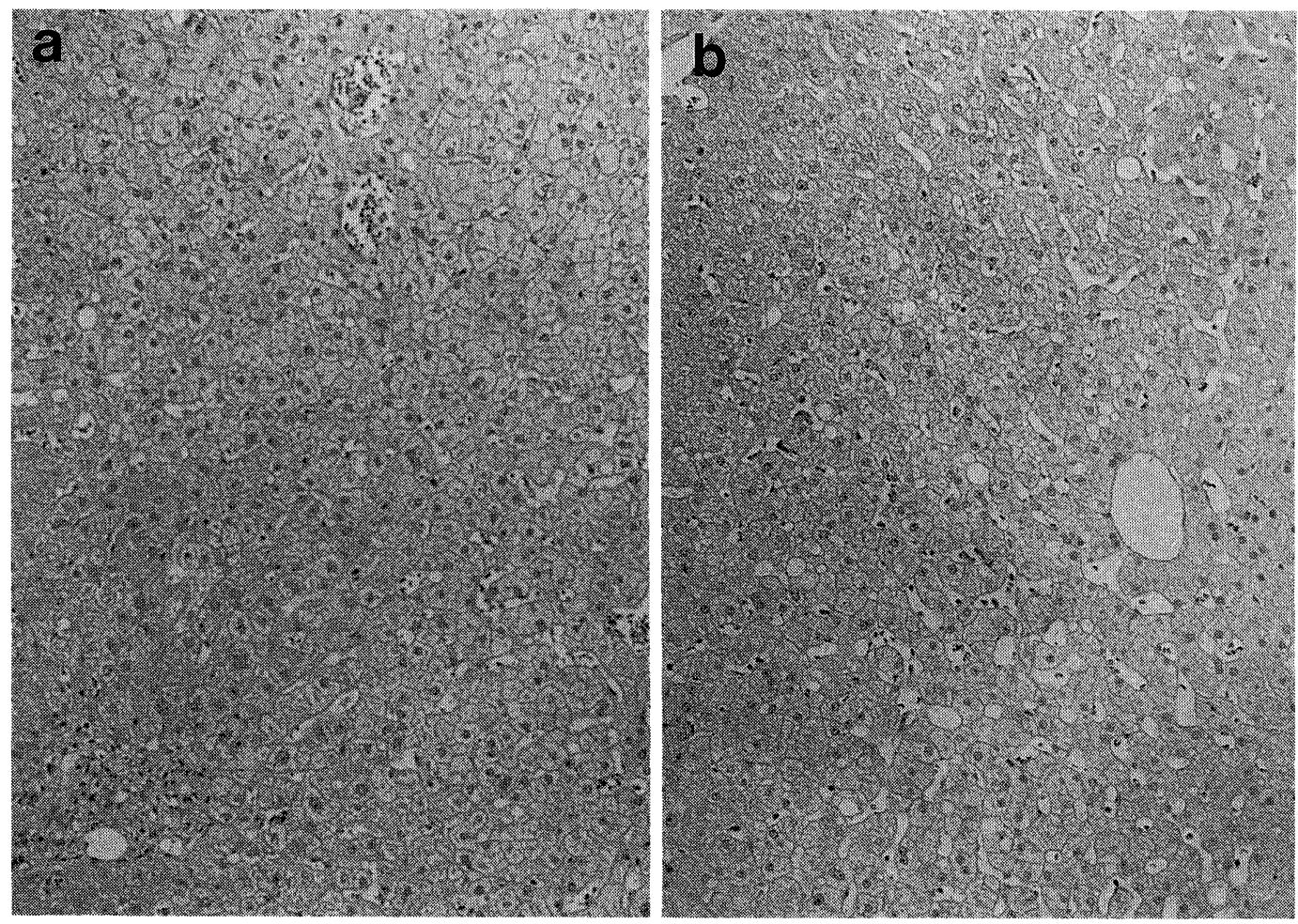

Fig. 5. Histological findings of the liver biopsy specimen before and after ethanol load. a) before taking ethanol (HE stain, $\times 80$ ). b) after taking ethanol (HE stain, $\times 80$ ). 


\section{LPL and HTGL in Hypertriglyceridemia}

factors for LPL and HTGL. If LPL and HTGL were decreased to compensate for an increase of TG, apoprotein C-II and $\mathrm{E}$ should decrease. But in this patient these apoproteins were increased, so the decrease of LPL and HTGL may not be a result, but a cause of TG increase.

The HDL-cholesterol level is decreased by ethanol loading in the presence of liver injury, while it generally increases in the absence of liver disease (6-8). Despite the absence of liver injury, low HDL-cholesterol levels were observed in the present patient throughout his hospital course, and they were not affected by ethanol loading. Glueck and associates (9) found that 2 weeks of ethanol loading at 35-53 g/day did not increase the HDL-cholesterol level in seven young male volunteers. In Belfrage and associates' study (10), when nine healthy males were given $75 \mathrm{~g}$ of ethanol per day for 5 weeks, significant increases in HDL-cholesterol appeared only 3 weeks after the intake of alcohol began. In the present patient, the short loading period could be partly responsible for the failure of increasing HDL-cholesterol level by ethanol. Another possible cause may be suggested by the report of Wilson and Lees (11), who found a negative correlation between TG and HDL-cholesterol concentrations both in vivo and in vitro, and speculated that HDL was formed from TG-enriched lipoprotein. In a patient with reduced LPL activity like the present patient, an elevation of the TG level and decreases in the HDL and HDL-cholesterol levels due to the reduced breakdown of TG-enriched lipoprotein is understandable.

Ethanol intake generally enhances the activity of Lglycerophosphate acyltransferase in the liver microsomes, and subsequent selective TG production from fatty acids causes augmentation of the hepatic synthesis and secretion of VLDL (12). The increased production and secretion of TG in the liver also seemed to be responsible for hypertriglyceridemia in the present patient. Moreover, the very high serum TG level $(5,120$ $\mathrm{mg} / \mathrm{dl}$ ) also suggested a possible role of the reduced activity of LPL and HTGL in his hypertriglyceridemia.

Alcohol intake can cause hypertriglyceridemia even in healthy individuals, mostly with a moderate increase in the serum TG level not exceeding $1,000 \mathrm{mg} / \mathrm{dl}$.

We report a habitual drinker who presented with an extremely high TG level $(5,120 \mathrm{mg} / \mathrm{dl})$ for which possibly the decreased levels of LPL and HTGL was considered to be responsible.

\section{References}

1) Brown MS, Goldstein JL. The hyperlipoproteinemias and other disorders of lipid metabolism. in: Harrison's Principles of Internal Medicine, 12th ed, Wilson JD, Braunwald E, Isselbacher KJ, et al, Eds. McGraw-Hill Book Company, New York, 1991, p. 1814.

2) Sabesin SM. Lipid and lipoprotein abnormalities in alcoholic liver disease. Circulation 64: 72, 1981.

3) Taskinen MR, Valimaki M, Nikkila EA, Kuusi T, Ehnholm C, Yikahri R. High density lipoprotein subfractions and postheparin plasma lipases in alcoholic men before and after ethanol withdrawal. Metabolism 31: $1168,1982$.

4) Crouse JR, Grundy SM. Effects of alcohol on plasma lipoproteins and cholesterol and triglyceride metabolism in man. J Lipid Res 25: 486, 1984.

5) Goldberg CS, Tall AR, Krumholz S. Acute inhibition of hepatic lipase and increase in plasma lipoproteins after alcohol intake. J Lipid Res 25: $714,1984$.

6) Castelli WP, Doyle JT, Gordon T, et al. Alcohol and blood lipids. Lancet 2: $153,1977$.

7) Danielsson B, Ekman R, Fex G, et al. Changes in plasma high density lipoproteins in chronic male alcoholics during and after abuse. Scand J Clin Lab Invest 38: 113, 1978.

8) Okamoto Y, Fujimori Y, Nakao H, Tsujii T. Role of the liver in alcoholinduced alteration of high-density lipoprotein metabolism. J Lab Clin Med 111: 482, 1988.

9) Glueck CJ, Hogg E, Allen C, Gartside PS. Effects of alcohol ingestion on lipid and lipoprotein in normal men: isocaloric metabolic studies. Am J Clin Nutr 23: 2287, 1980.

10) Belfrage $P, B e r g ~ B$, Hagerstrand I, Nilsson-Ehle $P$, Tornqvist $H$, Wiebe T. Alterations of lipid metabolism in healthy volunteers during long-term ethanol intake. Eur J Clin Invest 7: 127, 1977.

11) Wilson DE, Lees RS. Metabolic relationships among the plasma lipoproteins. J Clin Invest 51: 1051, 1972.

12) Alpers DH, Sabesin SM. Fatty liver: Biochemical and clinical aspects. in: Diseases of the Liver, 6th ed, Schiff L, Schiff ER, Eds. J. B. Lippincott Company, Philadelphia, 1987, p. 949. 